\title{
The progression of diversity: Black women in neurosurgery
}

\author{
Jean-Paul Bryant, MSc, ${ }^{1}$ Diana I. Nwokoye, MS, ${ }^{2}$ MaKayla F. Cox, ${ }^{3}$ and Nnenna S. Mbabuike, MD ${ }^{4}$ \\ ${ }^{1}$ University of Miami Miller School of Medicine, Miami, Florida; ${ }^{2}$ Howard University College of Medicine, Washington, DC; \\ ${ }^{3}$ Department of Chemistry, University of Illinois, Springfield, Illinois; and “Department of Neurosurgery, Ascension St. Mary's \\ Hospital, Saginaw, Michigan
}

\begin{abstract}
While diversity in organized medicine has undoubtedly improved, a disparity remains in the racial and gender makeup of its constituents. This disparity is not distributed equally among all specialties of practice. The surgical subspecialties exemplify this phenomenon by having large gaps between the number of women and racial/ethnic minorities compared to their majority counterparts. Pertaining to neurosurgery in the US, this gap is substantial, with women reaching minority status only within the last 2 years. Among international women in neurosurgery, Black women are even further underrepresented despite efforts in recent years to close the gender gap. The reason for this disparity is likely multifactorial, as Black women demonstrate a unique intersectionality as a minority in regard to both race and gender. In this study, the authors provide historical context for the current state of diversity in neurosurgery and the global strides made by Black women within the field. The authors report recurrent themes in the experiences of Black female neurosurgery attendings and residents as revealed through personal interviews. Furthermore, they examine factors that contribute to the disproportionate representation of Black women in neurosurgery.
\end{abstract}

https://thejns.org/doi/abs/10.3171/2020.12.FOCUS20945

KEYWORDS neurosurgery; women; diversity; history; Black

$\mathrm{T}$ $\mathrm{HE}$ foundation of global medicine is rooted in inequity and discrimination manifesting in the historical exclusivity of its membership. Despite recent progress in inclusivity, representation is still disproportional to the diversity reflected in the population. Within the US, women make up $35.2 \%$ of practicing physicians. ${ }^{1}$ In 2019, Black women represented $6.8 \%$ of the US population but represented $2.4 \%$ of all practicing physicians. ${ }^{2,3}$ Women make up only $12.98 \%$ of practicing surgeons in the US. ${ }^{4}$ Of this $12.98 \%$, Black women represent $0.074 \% .^{5}$ Internationally, women are also underrepresented within surgery and surgical subspecialties.${ }^{6,7}$ For example, in Australia women made up 50.7\% of medical graduates in 2016 but comprised less than $5 \%$ of all orthopedic surgeons. ${ }^{7}$ Within neurosurgery, women represent $9.16 \%$ of practicing neurosurgeons, with only $0.585 \%$ of all neurosurgeons identifying as both female and Black or African American. These numbers are even more disparate when we examine them globally. In 2017, West Africans celebrated their first indigenously trained Black female neurosurgeon, Dr. Salamat Ahuoiza Aliu. ${ }^{8}$

In this review, we seek to explore factors that contribute to the incommensurate inclusion of Black women in neurosurgery. To this aim, we discuss the history of women in medicine and neurosurgery, the Women in Neurosurgery (WINS) movement, and the global contributions of Black women in the field. Lastly, drawing on interviews conducted with Black female neurosurgery attendings and residents, we examine underrepresentation of Black women in neurosurgery and explore possible solutions for increasing diversity.

\section{Methods Literature Review}

The following key terms or phrases were entered into three databases, PubMed, ScienceDirect, and Google Scholar: "Black women in neurosurgery," "women in neurosurgery," and "diversity in neurosurgery." Articles were reviewed for content relevancy and cited if they pertained to the topic of interest.

\section{Data Gathering}

Data regarding the gender and racial/ethnic makeup of 


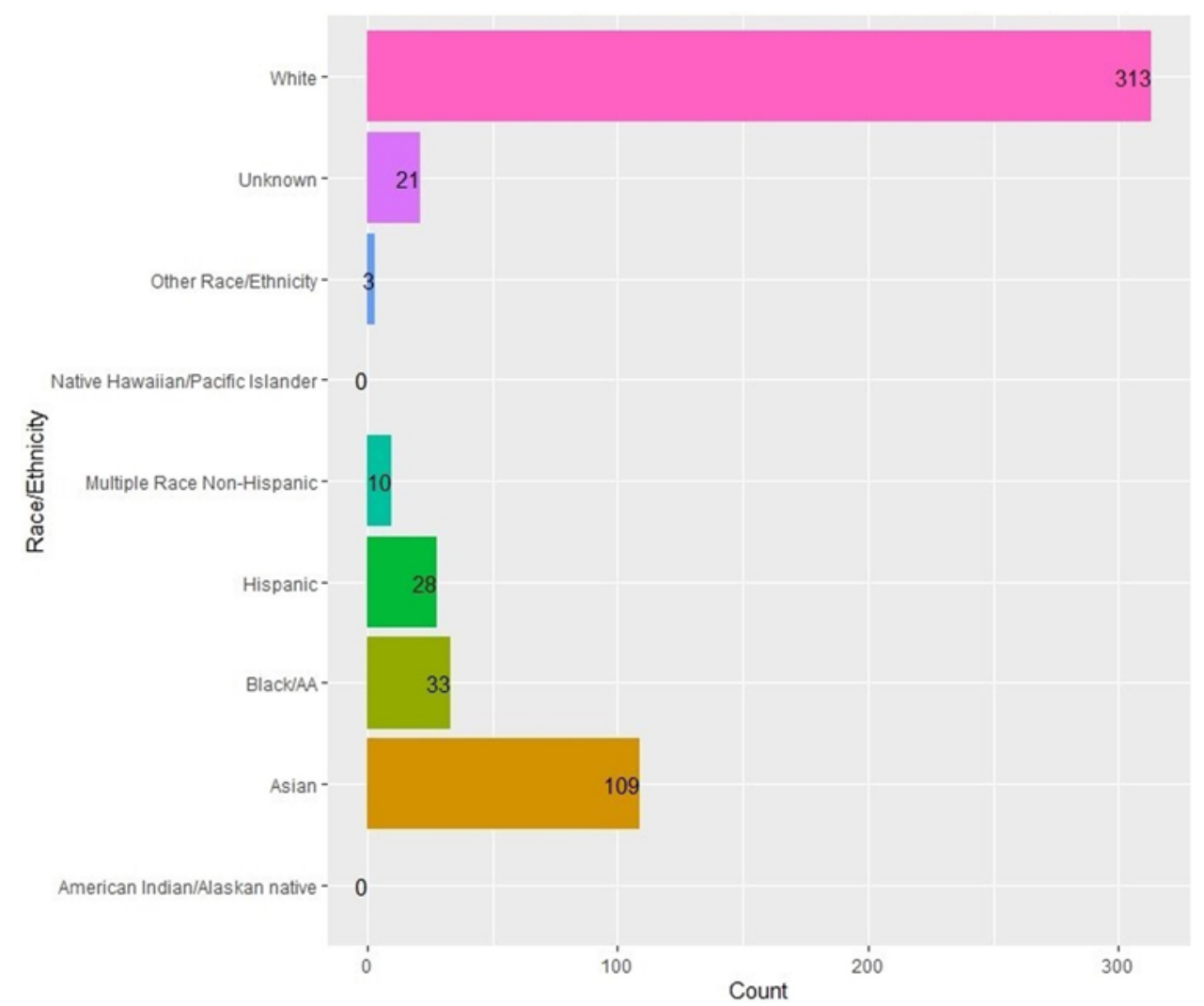

FIG. 1. Racial/ethnic makeup of practicing female neurosurgeons. $A A=$ African American.

current practicing neurosurgeons in the US were gathered from the annual Diversity in Medicine report produced by the Association of American Medical Colleges (AAMC) (Fig. 1). ${ }^{3}$ The most recent publication of this document was used in the tabulation of percentages of practicing female neurosurgeons.

\section{Interviews}

Inclusion criteria for interview subjects included 1) board-certified/board-eligible neurosurgeons or neurosurgical resident trainees in the US who 2) identified as Black and female; 3 ) received or are currently receiving their neurosurgical residency training in the US at an accredited program; and 4) were willing to participate in our questionnaire. Interviews were conducted via telephone or teleconference video; a standard question format was used during each interview, and answers were recorded. Subjects were given the option of having their answers used anonymously. Subjects were initially identified through professional societies and anecdotal recommendations to the authors.

\section{Results}

In 1849, Dr. Elizabeth Blackwell became the first female physician in the US. ${ }^{9}$ Fifteen years later, Dr. Rebecca Lee became the first Black female physician in the country in $1864 . .^{10,11}$ The late 1800 s and 1900 s would bring about pioneers in primary care and, subsequently, surgery and its subspecialties (Fig. 2). In the 20th century, Dr. Diana Beck is considered to have become the first female neurosurgeon in the world. Following in this path, Dr. Ayisima Altinok would become the first female neurosurgeon in Turkey, Dr. T. S. Kanaka would become the first in Asia, and in 1961, Dr. Ruth Kerr Jakoby would become the first diplomate of the American Board of Neurological Surgery (ABNS). ${ }^{12}$ This trend would extend to 1981, when Dr. Alexa Irene Canady became the first Black woman to graduate from a US neurosurgical residency program. ${ }^{13}$

\section{Pursuing Diversity Through the WINS Movement}

Neurosurgery consisted of only White men until the world's first female neurosurgeons entered the field in the 1940s in Germany, England, and Romania. ${ }^{14}$ Recognizing the need to organize and address this issue, 8 female neurosurgeons created WINS in 1979 with the mission to promote leadership and create a supportive environment for women to reach their professional and personal goals. ${ }^{15}$ In 2008, the American Association of Neurological Surgeons (AANS) asked WINS to publish a white paper detailing the obstacles faced by women in the field and recommendations on how to address them. ${ }^{16}$ That year, women accounted for less than a minority $(<15 \%)$ of all practicing neurosurgeons, and by 2018 women reached minority status..$^{17}$ Additionally, in 2009, women accounted for $12.2 \%$ of all training residents, increasing to $17.5 \%$ as 


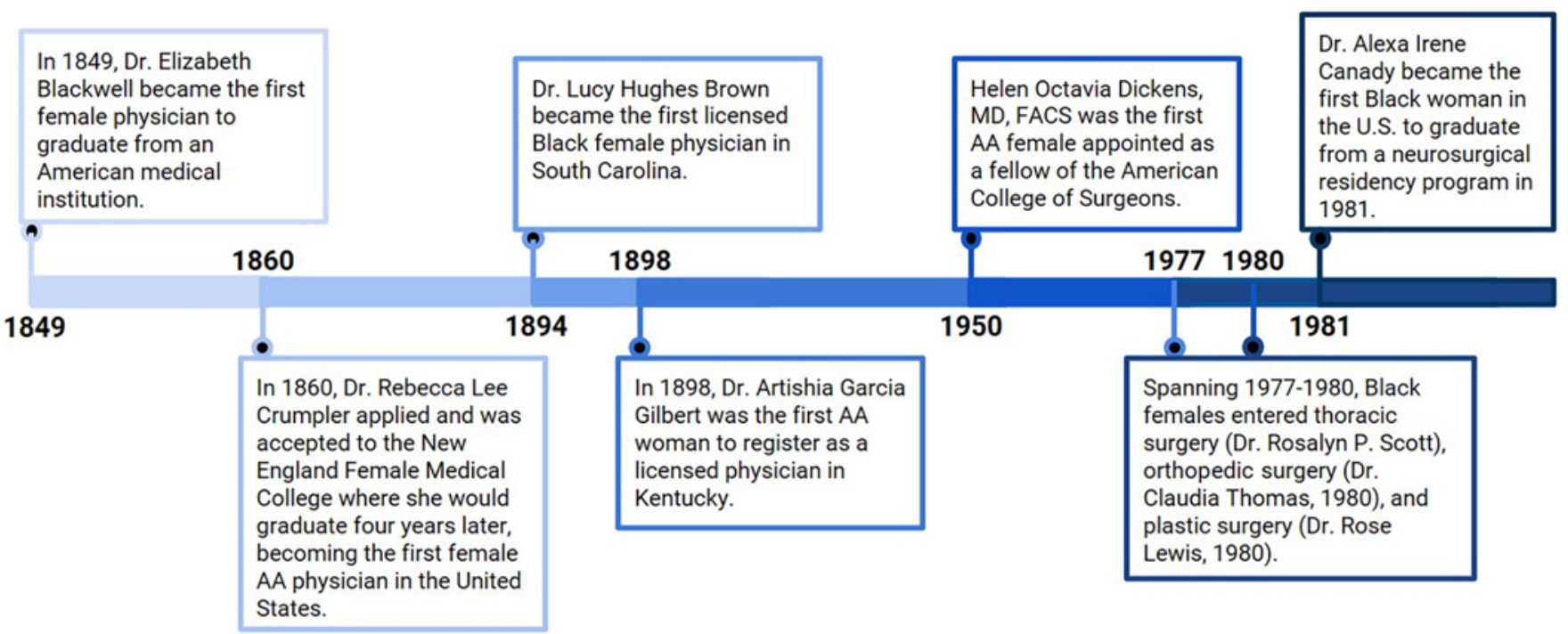

FIG. 2. Timeline displaying historical breakthroughs of Black women in medicine in the US. ${ }^{38-41}$ FACS $=$ Fellow of the American College of Surgeons.

of 2019.18.19 This demonstrates a 5.3\% increase compared with the $1.3 \%$ increase from the 1990 s to 2000 s. A direct result of this growth has been more women becoming department chairs and residency program directors. Dr. Shelly Timmons, a former WINS president, became the first female president of the AANS in 2018. Two women currently serve on the ABNS and Residency Review Committee. A publicly available database stratified by both race and gender for neurosurgery trainees was not found at the time of this publication.

\section{Historical Perspective on Black Women in Neurosurgery}

In 1981, Dr. Alexa Irene Canady became the first Black female neurosurgeon in the US as well as the first female neurosurgical graduate in the state of Minnesota. ${ }^{20,21} \mathrm{Dr}$. Canady practiced as a pediatric neurosurgeon where she served as the chief of neurosurgery at the Children's Hospital of Michigan from 1987 to 2001.

Shortly thereafter, in 1982, Dr. M. Deborah Hyde became the first female graduate from neurosurgery residency at Case Western Reserve University. Later, Dr. Hyde became the second Black woman to be certified by the ABNS. ${ }^{13}$ This would eventually give way to more recent milestones, the appointment of one of the first Black female full professors of neurological surgery in the US, and the first at Stanford University, Dr. Odette A. Harris.

The global contribution of Black women in neurosurgery is highlighted with recent milestones around the world. In 2018, Dr. Juliet Sekabunga became the first board-certified neurosurgeon in Uganda, Africa. Prior to Dr. Sekabunga, there were only 6 male neurosurgeons in all of Uganda as of 2016.22

In 2018, Dr. Claire Karekezi became the first female neurosurgeon in Rwanda, where there currently are only 6 neurosurgeons for a country of 12 million people. ${ }^{23}$ Dr. Karekezi graduated as a neurosurgeon from the Mohamed V. University-World Federation of Neurosurgical Soci- eties Rabat Training Center for African Neurosurgeons in Morocco, Africa. ${ }^{23}$ She cites mentorship as crucial to her unprecedented entrance into this profession and has trained with neurosurgeons at institutions worldwide, including Oxford, the University of Toronto, Brigham and Women's Hospital, and Mount Sinai Hospital. Dr. Karekezi is largely credited with building the neurosurgery program in Rwanda and remains operatively busy. Additionally, she hopes to mentor and advocate for the younger generation of girls in Rwanda to achieve their ultimate professional goals. ${ }^{23}$

While the WINS movement has gained significant momentum in recent years, a disparity remains between the number of Black women in neurosurgery and their White counterparts. One potential factor contributing to this gap, which was highlighted during our interviews with Black female US neurosurgeons, was the lack of conversation regarding racial inclusivity within the WINS agenda. Notably, WINS did not address racial equity or inclusivity in their 2008 paper.

\section{Interviews With Black Female Neurosurgeons}

We identified 3 attending neurosurgeons and 2 neurosurgical trainees who met our inclusion criteria. The 3 board-certified attending neurosurgeons have experience as attending physicians ranging from 4 to 12 years. The 2 neurosurgical residents are junior-level trainees, who chose to remain anonymous, but were agreeable to participating in the present study.

The 3 attending neurosurgeons interviewed were Dr. Odette A. Harris, Dr. Keyne K. Johnson, and Dr. Laura B. Ngwenya. Dr. Harris is the director of brain injury and professor of neurosurgery at Stanford University; she specializes in traumatic brain injury (TBI) and disorders of the peripheral nervous system. Dr. Johnson is a pediatric neurosurgeon and owner of the Brain and Spine Institute for Children in Orlando, Florida. Her clinical interests 
include congenital central nervous system disorders and complex spinal deformities. Dr. Ngwenya is an assistant professor of neurosurgery and director of neurotrauma at the University of Cincinnati College of Medicine. Her clinical areas of focus include TBI, spine injury, and general neurosurgical conditions.

\section{Experiences of Black Women in Neurosurgery}

Dr. Harris, who was the only Black female in her graduating classes and training departments, noted the sense of isolation these situations can create for herself and other Black women in similar settings. She further described being asked to clean operating rooms while wearing scrubs and recounted that people have mistaken her credentials, MD, to mean Maryland rather than medical doctor. During our interview, she revealed that she is asked, "Where did you train?" more frequently than her White counterparts, implying that she is somehow less qualified in comparison to her colleagues.

\section{Representation}

Dr. Johnson was inspired by Dr. Ben Carson's work and declared that she would become a pediatric neurosurgeon. She became the first Black woman to graduate from the Duke University neurosurgical residency and followed with a fellowship in pediatric neurosurgery at Texas Children's Hospital. She admitted that she saw few Black female neurosurgeons throughout her academic journey. To attract more Black women to the field, she explained that "students early in their educational career would benefit from viewing others of the same demographic achieving success in neurosurgery."

\section{Global Representation Is Key to Increasing the Footprint of Black Women in International Neurosurgery}

In 2003, Dr. Harris was awarded the William P. Van Wagenen Fellowship, an award that affords senior neurosurgical residents the opportunity to conduct research abroad. ${ }^{24}$ She worked in the University Hospital of the West Indies in Jamaica studying epidemiological trends and outcomes in TBI as a means to develop effective clinical protocols that would maximize available resources in a developing country. ${ }^{24,25}$ Since completing her fellowship, she has maintained an appointment as a visiting consultant in neurosurgery in Jamaica. ${ }^{26}$ Furthermore, she has collaborated with the Jamaican National Road Safety Council to establish a ThinkFirst chapter in Jamaica that provides education on the risk and prevention of spinal and brain traumatic injuries. ${ }^{24,27}$ Her invaluable contributions have garnered her the National Road Safety Council Award from the prime minister and minister of health of Jamaica, and the Scientific Award from the Caribbean Association Neuroscience Symposium/University Hospital of the West Indies. ${ }^{28}$

\section{Advantages of Increasing Diversity}

Dr. Ngwenya highlighted the value of Black female physicians advocating for Black patients when doing so is often regarded as one of the most important aspects of patient care. ${ }^{29}$ She expressed that her patients and their families were typically fearful during their visits, as referrals to neurosurgeons are often associated with life-altering diagnoses. She felt able to connect with the African American community as they cultivated a bond founded on cultural similarities.

\section{Mentorship}

For Dr. Harris, Dr. John Adler and Dr. Lawrence Shuer have been long-term mentors, guiding her through "important career decisions and assisting to keep [her] excited and motivated." She also disclosed her desire to mentor young Black females as a reason she chose to pursue a career in academic neurosurgery. Other interviewees remarked that mentors have been their strongest advocates, especially during moments of doubt and difficulty. It is noted that great mentors are not limited to those of similar demographic or gender. However, one interviewee spoke of her unique relationship with a Black female neurosurgeon, describing this relationship as the most "honest and open." She also noted that it affords her the opportunity to see someone excel in neurosurgery that she identifies with on the basis of race, gender, and shared experiences.

\section{Retention}

One interviewee gave a disheartening account of her experience that almost led to her withdraw from her training program. During training, numerous allegations were filed against this interviewee by other departments despite clear traceable documentation to the contrary. Repeated complaints compounded by the emotional exhaustion, mental distress, and "feeling like a burden to her department and co-residents" led her to feel defeated and discouraged. Her documentation and the indispensable support from her program's leadership fortunately enabled her tenure to not result in dismissal or withdrawal. However, one interviewee noted that other Black medicine residents across different specialties, including neurosurgical residents, have faced similar situations as mentioned above and have allegedly been dismissed when not otherwise supported by their department.

\section{Discussion}

Inclusivity and diversity have been episodic topics in the field of medicine, centered on changing the makeup of its constituents to reflect that of the population it serves. As a formal subsociety, WINS has increased efforts to not only include women in the field of neurosurgery but also to raise them to levels of leadership and influence. However, despite these efforts, we hypothesize that the experience of Black women within the field has not mirrored the trends for inclusivity of women overall in the field. Black women continue to make significant contributions to the discipline internationally while holding a persistently marginalized position within the field. The worldwide experiences of the Black women in neurosurgery presented here demonstrate a unique intersectional reality when dealing with discrimination based on both gender and race.

Higher incidences of racial discrimination are a strong contributor to increased feelings of burnout and eventual attrition found among general surgical residents and 
medical students..$^{30}$ Feelings of burnout were traced to environmental factors rather than the learner's attributes. ${ }^{31}$ Furthermore, $70 \%$ of Black general surgical residents reported having faced racial discrimination, the highest of all racial/ethnic groups. ${ }^{32}$ When compared by gender across races, Black female residents reported the highest rates of racial discrimination. While data on attrition rates stratified by race are not published for neurosurgery, it is well documented that female neurosurgical residents consistently have higher attrition rates than males. ${ }^{33,34}$

Women and minorities are traditionally treated as mutually exclusive groups that share the commonality of marginalization and discrimination. In efforts at inclusion, there are often actions that aim to increase the number of women or number of people of color within a certain space. However, Black women stand at a unique threshold where they encounter the sexism and racial discrimination that White women and Black men do not experience, respectively. ${ }^{35}$ In an essay that explores increasing the representation of women and men of color in academic medicine, Kimberly A. Griffin broached the topic of the intersectionality of being both a woman and a person of color. ${ }^{35}$ As described in our interviews with Black female neurosurgeons, this leads to lived experiences that are not entirely addressed by the movement for either gender equality or racial diversity. Despite the commendable efforts of WINS, the lived experiences of Black women in neurosurgery continue to reflect a marginalization that often cannot be pinned down to an implicit bias rooted in either their gender or race, or both.

Dr. Bowleg, a public health advocate, postulated in 2012 that understanding intersectionality as a theoretical basis was key to improving public health policy. ${ }^{36}$ This implies that understanding the way in which seemingly separate social identities in one individual may influence how they are perceived and treated affects the ways disparities in health are managed. Many people can identify as members of different marginalized groups at one point in time-a female immigrant, a male of color with a disability, etc. Dr. Bowleg uses homicide as an example. At the time of publication, homicide was not listed as a leading cause of death for all men; however, it was listed as the fifth leading cause of death among Black men. Understanding how Black men are disproportionately affected from the overall male population exposes a social inequality that can only be addressed once it is recognized. ${ }^{36}$

Similarly, recognizing that Black women may not be rising in representation within the field of neurosurgery in the same way their male counterparts of color or other women are allows for an opportunity to address this inequity by 1) opening the discipline to a wider pool of capable and competent applicants who stand to contribute to the excellence of the field; 2) improving the care of patients of similar backgrounds through shared cultural appreciation; and 3) empowering the emergence of a marginalized population, and thereby improving inclusion of other marginalized populations.

Solutions to the disproportionate rate at which Black women are rising in the field are not to be considered simple, but rather complex, and as such require an investment in complete understanding of the inequity in order to address it thoroughly. These include efforts to affect recruitment and retention through mentorship and pipeline programs. However, in addition to providing early exposure to the field, it would be beneficial if designers of such programs were to address issues faced by Black women in neurosurgery. An example of such a program is the Doctors Reaching Minority Males Exploring Neuroscience (Dr. MMEN) summer program at the Mount Sinai Hospital. Founded by a Black male neurosurgeon, the program targets Black and Latino high school males in order to provide mentorship, research and clinical experience, operating room exposure, and professional development. Similarly, Bettinger and Long found that women were more likely to take extra academic courses when they were taught by female faculty. ${ }^{37}$ This speaks to the power of representation of faculty with similar identities and its ability to encourage advanced scholastic pursuits among those marginally represented in professional spaces.

Solutions should not be limited to one or two; therefore, we propose the following efforts to elevate the presence of Black women in neurosurgery:

1) Research initiatives supported by data collection with the AAMC in conjunction with the ABNS, AANS, and Congress of Neurological Surgeons. This includes measuring the cross-composite of race and gender of those who are matriculated into or graduated, withdrawn, or otherwise dismissed from neurosurgical residency programs. Following this same composite in academic neurosurgical institutions, including organized neurosurgical societies, will allow us to measure equity in how leadership and positions of influence are distributed among members of this discipline;

2) Implicit bias training with regard to how undergraduate and medical students are recruited, neurosurgical residents are trained, and the way in which neurosurgical faculty are promoted within neurosurgery;

3) Mentorship and recruitment of Black women through formal pipeline programs and interest groups in conjunction with WINS, the Student National Medical Association, the American Medical Women's Association, and the Society of Black Academic Surgeons;

4) Global outreach in conjunction with WINS and the Continental Association of African Neurosurgical Societies to provide mentorship, observerships, and international training to Black females seeking a career in neurosurgery within their own countries; and

5) Deliberate promotion of Black women into positions of leadership and influence in organized neurosurgery through intentional consideration of those qualified for such positions, and focused engagement of Black women early and frequently in leadership training measures and professional paths toward tenure.

The limitations of this study primarily involve the study design. The authors recognize that a small sample of Black female neurosurgeons was interviewed, which does not reflect the experiences of the entire cohort of Black women in neurosurgery in the US or abroad. The paucity in published data specifically examining the breakdown by gender, and further by race, of residents within neurosurgery serves as a limitation in substantiating our hy- 
pothesis: that the representation of Black women in neurosurgery has lagged behind that of overall women in neurosurgery. This gap in data collection, however, leaves room for further research efforts into the matter.

Furthermore, the intersectionality of gender and race among our group of interest renders it impossible to distinguish between which factors are leading to underrepresentation in the field. Finally, given that the authors chose the interviewees and conducted interviews based on responses from the neurosurgeons, both selection and response bias are inherent in the present study.

\section{Conclusions}

While diversity in neurosurgery and medicine at-large has steadily increased, a significant disparity still exists between minority physicians and their majority counterparts worldwide. Specifically, in neurosurgery the number of women who identify as Black has remained substantially low. Efforts to increase this number, and subsequently reduce this gap, will benefit not only individual neurosurgical departments but also the field as a whole.

\section{Acknowledgments}

We would like to express our deepest gratitude to the wonderful women who graciously lent their voices in the crafting of this paper. Thank you for allowing us to bring an audience to your experiences. We hope that this paper opens conversation for the change we hope to see.

\section{References}

1. Practice specialty, females by race/ethnicity, 2018. Diversity in Medicine. Facts and Figures 2019. AAMC. Accessed January 19, 2021. https://www.aamc.org/data-reports/workforce/ data/table-12-practice-specialty-females-race/ethnicity-2018

2. McKinnon JD, Bennett CE. We the People. Blacks in the United States. Census 2000 Special Reports. US Census Bureau; 2005. Accessed January 19, 2021. https://www.census. gov/prod/2005pubs/censr-25.pdf

3. Percentage of physicians by sex and race/ethnicity, 2018. Diversity in Medicine. Facts and Figures 2019. AAMC. Accessed January 19, 2021. https://www.aamc.org/data-reports/ workforce/interactive-data/figure-20-percentage-physicianssex-and-race/ethnicity-2018

4. Active physicians by sex and specialty, 2017. Physician Specialty Data Report. AAMC. Accessed January 19, 2021. https://www.aamc.org/data-reports/workforce/interactivedata/active-physicians-sex-and-specialty-2017

5. Practice specialty, males by race/ethnicity, 2018. Diversity in Medicine. Facts and Figures 2019. AAMC. Accessed January 19, 2021. https://www.aamc.org/data-reports/workforce/data/ table-13-practice-specialty-males-race/ethnicity-2018

6. de Costa J, Chen-Xu J, Bentounsi Z, Vervoort D. Women in surgery: challenges and opportunities. Int J Surg Global Health. 2018;1:e02.

7. Emery SE. Diversity in orthopaedic surgery: international perspectives: AOA critical issues. J Bone Joint Surg Am. 2019;101(21):e113.

8. Nigeria's first indigenous female neurosurgeon. Dr. Salamat Ahuoiza Aliu. CFR Magazine. 2018. Accessed January 13, 2021. https://www.cfrmagazine.com/2017/10/nigerias-first-indigenous-female-neurosurgeon-dr-salamat-ahuoiza-aliu.html

9. Tan SY, Tasaki A. Elizabeth Blackwell (1821-1910): America's first woman doctor. Singapore Med J. 2006;47(9): 739-740.
10. Webster RB. African American Firsts in Science \& Technology. Gale Group; 1999.

11. Davidson J. Women, reform, and medical leadership. In: Davidson J, ed. A Century of Homeopaths: Their Influence on Medicine and Health. Springer New York; 2014:9-28.

12. Spetzler RF. Progress of women in neurosurgery. Asian J Neurosurg. 2011;6(1):6-12.

13. McClelland S III. M. Deborrah Hyde, MD, MS: the second African-American female neurosurgeon. J Natl Med Assoc. 2007;99(10):1193-1195.

14. Kim EE, Klein AL, Lartigue JW, et al. Diversity in neurosurgery. World Neurosurg. 2021;145:197-204.

15. Mission statement. Women in Neursourgery (WINS). Accessed January 13, 2021. http://www.neurosurgerywins.org/ welcome

16. Benzil DL, Abosch A, Germano I, et al. The future of neurosurgery: a white paper on the recruitment and retention of women in neurosurgery. J Neurosurg. 2008;109(3):378386.

17. Corley J, Williamson T. Women in neurosurgery: final frontier of career women's movement. World Neurosurg. 2018; 111:130-131.

18. Brotherton SE, Etzel SI. Graduate medical education, 20092010. JAMA. 2010;304(11):1255-1270.

19. Brotherton SE, Etzel SI. Graduate medical education, 20192020. JAMA. 2020;324(12):1230-1250.

20. McClelland S III. Alexa Irene Canady: the first AfricanAmerican woman neurosurgeon. J Natl Med Assoc. 2008; 100(4):439-443.

21. Dr. Alexa Irene Canady. Changing the Face of Medicine. Accessed January 13, 2021. https://cfmedicine.nlm.nih.gov/ physicians/biography_53.html

22. Fuller A, Tran T, Muhumuza M, Haglund MM. Building neurosurgical capacity in low and middle income countries. eNeurologicalSci. 2015;3:1-6.

23. Matemavi P. Passion and Purpose. Black Female Surgeons. A 2 Z Press; 2020.

24. Van Wagenen Fellowship. AANS.org. Accessed January 13, 2021. https://www.aans.org/en/Trainees/Grants-andFellowships/Van-Wagenen-Fellowship/William-P-VanWagenen-MD

25. Odette Harris. Aspen Global Leadership Network. Accessed January 19, 2021. https://agln.aspeninstitute.org/profile/4597

26. Harris OA, Bruce CA, Reid M, et al. Examination of the management of traumatic brain injury in the developing and developed world: focus on resource utilization, protocols, and practices that alter outcome. J Neurosurg. 2008;109(3): 433-438.

27. Think First Program. National Road Safety Council. Accessed January 13, 2021. http://www.nationalroadsafetycouncil.org. jm/think.html

28. Odette Harris, MD, MPH. Stanford.edu. Accessed January 13, 2021. https://profiles.stanford.edu/odette-harris

29. Davoodvand S, Abbaszadeh A, Ahmadi F. Patient advocacy from the clinical nurses' viewpoint: a qualitative study. $J$ Med Ethics Hist Med. 2016;9:5.

30. Dyrbye LN, Thomas MR, Eacker A, et al. Race, ethnicity, and medical student well-being in the United States. Arch Intern Med. 2007;167(19):2103-2109.

31. Dyrbye LN, Wittlin NM, Hardeman RR, et al. A prognostic index to identify the risk of developing depression symptoms among U.S. medical students derived from a national, fouryear longitudinal study. Acad Med. 2019;94(2):217-226.

32. Yuce TK, Turner PL, Glass C, et al. National evaluation of racial/ethnic discrimination in US surgical residency programs. JAMA Surg. 2020;155(6):526-528.

33. Agarwal N, White MD, Pannullo SC, Chambless LB. Analysis of national trends in neurosurgical resident attrition. $J$ Neurosurg. 2019;131(5):1668-1673. 
34. Lynch G, Nieto K, Puthenveettil S, et al. Attrition rates in neurosurgery residency: analysis of 1361 consecutive residents matched from 1990 to 1999. J Neurosurg. 2015;122(2): 240-249.

35. Griffin KA. Institutional barriers, strategies, and benefits to increasing the representation of women and men of color in the professoriate. In: Perna LW, ed. Higher Education: Handbook of Theory and Research. Vol 35. Springer International Publishing; 2020:277-349.

36. Bowleg L. The problem with the phrase women and minorities: intersectionality - an important theoretical framework for public health. Am J Public Health. 2012;102:1267-1273.

37. Bettinger EP, Long BT. Do faculty serve as role models? The impact of instructor gender on female students. Am Econ Rev. 2005;95:152-157.

38. Helen Octavia Dickens, MD, FACS (1909-2001). American College of Surgeons. Accessed January 13, 2021. https:// www.facs.org/about-acs/archives/pasthighlights/dickens

39. Dr. Rosalyn P. Scott. Changing the Face of Medicine. Accessed January 13, 2021. https://cfmedicine.nlm.nih.gov/ physicians/biography_288.html

40. Emery CR. Against All Odds: Celebrating Black Women in Medicine. URU The Right To Be; 2015.
41. Alumni Profiles: Dr. Rose Lewis '60. Sacred Heart Cathedral Preparatory. Accessed January 13, 2021. https://www.shcp. edu/alumni-profiles/dr-rose-lewis-60

\section{Disclosures}

The authors report no conflict of interest concerning the materials or methods used in this study or the findings specified in this paper.

\section{Author Contributions}

Conception and design: Bryant. Acquisition of data: Mbabuike. Analysis and interpretation of data: Cox. Drafting the article: all authors. Critically revising the article: Mbabuike, Nwokoye, Cox. Reviewed submitted version of manuscript: Bryant, Nwokoye. Approved the final version of the manuscript on behalf of all authors: Mbabuike.

\section{Correspondence}

Nnenna S. Mbabuike: Ascension St. Mary's Hospital, Saginaw, MI.nnenna.mbabuike@ascension.org. 